\title{
Podcasts de divulgação científica: levantamento exploratório dos formatos de programas brasileiros
}

\section{Science communication podcasts: exploratory research of Brazilian program formats}

\section{Podcasts de divulgación científica: investigación exploratoria de formatos de programas brasileños}

\author{
Ana Cristina Peixoto Figueira ${ }^{1, a}$ \\ anacrisfigueira@yahoo.com.br | https://orcid.org/0000-0002-0037-8455 \\ Diego Vaz Bevilaqua ${ }^{2, b}$ \\ diego.bevilaqua@fiocruz.br | https://orcid.org/0000-0003-4822-4874 \\ ${ }^{1}$ Fundação Oswaldo Cruz, Canal Saúde. Rio de Janeiro, RJ, Brasil. \\ 2 Fundação Oswaldo Cruz, Casa de Oswaldo Cruz. Rio de Janeiro, RJ, Brasil. \\ a Especialização em Divulgação e Popularização da Ciência pela Fundação Oswaldo Cruz. \\ ${ }^{\text {b }}$ Doutorado em Física pela Universidade Federal do Rio de Janeiro.
}

\section{RESUMO}

A pesquisa apresentada neste artigo foi realizada com o objetivo de estudar os formatos de podcasts brasileiros de divulgação científica e identificar quais estilos são predominantes nessa produção de conteúdo. O estudo se caracteriza como um levantamento exploratório, que procurou sistematizar o objeto estudado usando uma abordagem qualiquantitativa. No levantamento da pesquisa foram identificados 69 podcasts, dos quais 37 foram selecionados para análise. Os critérios para a seleção foram popularidade, regularidade na publicação e longevidade. Ao todo, foram ouvidos 109 episódios. O resultado da pesquisa apontou que, dos formatos de podcast encontrados, o bate-papo ou mesacast é o principal modelo adotado seguido da entrevista e a maior parte das produções tem sido realizada por universidades ou cientistas independentes.

Palavras-chave: Comunicação e divulgação científica; Ciência; Podcast; Comunicação; Blogging.

\begin{abstract}
The research presented in this article aimed to study the formats of Brazilian podcasts for science communication and to identify which styles are most prevalent in this content production. The study is based on an exploratory research, which sought to systematize the studied object, by means of a qualitative and quantitative approach. It was identified in the research a total of 69 podcasts, 37 of which were selected for analysis. The selection criteria were popularity, regularity of publication and longevity. A total of 109 episodes were heard. The research showed that chat (also known as mesacast) stands out from all the other formats, followed by the interview, and that the most of the productions have been carrying out by universities or independent scientists.
\end{abstract}

Keywords: Scientific communication and diffusion; Science; Podcast; Communication; Blogging. 


\section{RESUMEN}

La investigación presentada en este artículo ha sido realizada con el objetivo de estudiar los formatos de los podcasts brasileños para la divulgación científica e de identificar cuáles estilos que más prevalecen en esta producción de contenidos. La investigación se caracteriza por ser una búsqueda exploratoria, que ha procurado sistematizar el objeto estudiado, valiéndose de un enfoque cualitativo y cuantitativo. En la investigación, se identificaron 69 podcasts, 37 de los cuales fueron seleccionados para análisis. Los criterios de selección fueron popularidad, regularidad de publicación y longevidad. Un total de 109 episodios fueron escuchados. El resultado de la investigación mostró que, de los formatos de podcast encontrados, se destaca el chat o mesacast, seguido de la entrevista. La mayoría de las producciones actualmente es realizada por universidades o científicos independientes.

Palabras clave: Comunicación y divulgación científica; Ciencia; Podcast; Comunicación; Blogging.

Contribuição dos autores:

Concepção e desenho do estudo: Ana Cristina Peixoto Figueira e Diego Vaz Bevilaqua.

Aquisição, análise ou interpretação dos dados: Ana Cristina Peixoto Figueira.

Redação do manuscrito: Ana Cristina Peixoto Figueira.

Revisão crítica do conteúdo intelectual: Diego Vaz Bevilaqua.

Declaração de conflito de interesses: não há.

Fontes de financiamento: não houve.

Considerações éticas: não há.

Agradecimentos/Contribuições adicionais: não há.

Histórico do artigo: submetido: 12 jul. 2021 | aceito: 08 fev. 2022 | publicado: 25 fev. 2022.

Apresentação anterior: $\mathrm{O}$ artigo é um desdobramento da monografia apresentada para especialização da primeira autora, orientada pelo segundo autor.

Licença CC BY-NC atribuição não comercial. Com essa licença é permitido acessar, baixar (download), copiar, imprimir, compartilhar, reutilizar e distribuir os artigos, desde que para uso não comercial e com a citação da fonte, conferindo os devidos créditos de autoria e menção à Reciis. Nesses casos, nenhuma permissão é necessária por parte dos autores ou dos editores. 


\section{INTRODUÇÃO}

A ferramenta de áudio é uma aposta para aproximar o indivíduo do conhecimento de forma lúdica e, dependendo do formato, inteligível. O formato dos programas traz as variações das vozes, dos estilos, das leituras como pano de fundo para tornar a experiência auditiva mais agradável. Cris Bartis, cofundadora do Mamilos Podcast, afirma que o podcast é a plataforma mais democrática de produção de conteúdo disponível atualmente. Segundo Bartis,

É uma mídia de acompanhamento. Ela não interrompe, ela não pede para você parar, ela te acompanha e como as pessoas estão cada vez mais em movimento, os momentos de consumo estão garantidos. Fora isso o podcast tem um charme difícil de mensurar, é uma relação com a voz, que nos remete à infância. Não tem o visual para se criar um conceito em cima de quem está falando, tem apenas o som e isso pode ser uma poderosa ferramenta de aproximação (BARTIS, 2018).

O podcast é uma ferramenta de comunicação com potencial para atrair a atenção do público e proporcionar acesso ao conhecimento, sem exigir grande esforço do ouvinte. Entre seus benefícios estão arquivos leves para baixar ou ouvir por streaming; mobilidade do ouvinte; possibilidade de pausar e escutar o programa quando puder (atemporalidade); e informação mais clara com o uso de linguagem coloquial.

Esse modelo de mídia vem se popularizando desde 2010. Pesquisa realizada em 2019 pelo Instituto Brasileiro de Opinião Pública e Estatística (Ibope), aponta que dos 120 milhões de internautas brasileiros, 16 milhões (19\%) escutam podcast diariamente, além de apresentar o celular como o dispositivo mais utilizado para o consumo dos áudios (PACETE, 2019). Na recente crise da pandemia do coronavírus, o podcast foi utilizado extensamente para tratar o tema, permitindo que cientistas pudessem se comunicar diretamente com o público (BRÜGGEMANN; LÖRCHER; WALTER, 2020; SILVA; D’ANDREA, 2020).

A palavra podcasting é a junção dos termos Ipod, marca de aparelho de reprodução de áudio da Apple, e broadcasting, que significa radiodifusão. Podcasting é a forma de publicação do podcast, um arquivo digital de áudio transmitido por meio de internet, seguindo um padrão de feed RSS (BONINI, 2020). A primeira experiência conhecida, cujo princípio era parecido com o do podcast atual, se deu nos anos 1980 nos Estados Unidos; período anterior à inserção da internet no cotidiano das pessoas. O chamado RCS (Radio Computer Services) era um serviço que fornecia software para gravar músicas e conversas em áudio no formato digital destinadas às estações de rádio. Esse serviço não permitia que qualquer pessoa gravasse e distribuísse seu conteúdo em áudio, mas inovava na digitalização da mídia auditiva (POLITI; ROSA, 2019).

O americano Carl Malamud utilizou o mesmo princípio em 1993, criando seu talk show gravado em arquivo digital e distribuído às pessoas em disquete. A iniciativa é considerada o primeiro 'podcast', mesmo que na ocasião ainda não existisse o nome e sem que houvesse o aparato tecnológico para o fácil acesso ao arquivo de áudio. Malamud explicava, para quem conseguisse abrir o arquivo, que a grande vantagem do formato era poder pausar a qualquer momento (POLITI; ROSA, 2019).

Um marco para os podcasts foi a criação do RSS (Really Simple Syndication) em meados dos anos 2000. É um script que avisa quando um novo conteúdo é publicado na internet, disponibilizando sua atualização. O sistema RSS atualmente está em sua versão 2.0, mas ele já teve versões anteriores com os nomes Rich Site Summary (RSS 0.91) e RDF Site Summary (RSS 0.9 E 1.0). No início, a criação do RSS estava relacionada aos blogs em áudio que, na época, ganhavam notoriedade. Essa é a razão de os podcasts terem ficado conhecidos, entre 2003 e 2005, como audioblogging (POLITI; ROSA, 2019).

Em outubro de 2003, o programador e empresário Dave Winer organizou um evento sobre blog na Universidade de Harvard. Na mesma ocasião, o VJ da MTV, Adam Curry, publicou em seu blog um tutorial sobre como fazer a gravação de um arquivo de MP3 em um Ipod por meio do RSS. A ideia de publicar 
um arquivo de $\mathrm{MP}_{3}$, via RSS, dentro de reprodutores de áudio como o Ipod gerou uma nova forma de distribuição de conteúdo de áudio. O conceito de agregador vem da iniciativa do usuário de agregar as atualizações de diferentes programas de MP3 (arquivos digitais de áudio) em um só lugar e não mais ter que baixar de um site e ouvir no computador. Vale registrar que o referido conceito surgiu, em 2000, quando a iGo lançou o programa MyAudio2Go com as funcionalidades conhecidas hoje, mas feito para PCs que tinham conexão lenta com a internet. O programa baixava arquivos de MP3 de notícias de esportes, entretenimento, clima e cultura em vez de músicas e durou apenas um ano até a empresa falir (POLITI; ROSA, 2019).

Após inúmeros experimentos acerca da distribuição de arquivos de áudio, na década de 2010, foram criadas as plataformas de streaming, como o Spotify, Deezer, SoundCloud, Castbox, Google Podcasts. Até então, as plataformas de streaming eram utilizadas apenas para compartilhamento de vídeos. A inserção dos podcasts facilitou o acesso aos arquivos, pois não era mais necessário obter um navegador específico para ouvi-los, e resultou no crescimento de sua popularidade. Se essas plataformas comerciais facilitaram o acesso ao conteúdo dos podcasts, também impulsionaram a profissionalização e os aspectos comerciais dos podcasts. Da ideia democrática e de libertação que dominava nos primeiros anos dos podcasts, desde 2012 a sua utilização vem sendo apropriada pelos grandes grupos comerciais da mídia, que têm lançado produtos que passaram a se sustentar comercialmente. Segundo Bonini (2020, p. 28): "O que está acontecendo com o podcasting, 11 anos após sua invenção, é a sua transformação de um meio de nicho, amador, "faça-vocêmesmo', para um meio comercial massivo: do narrowcasting ao broadcasting."

Por outro lado, essas plataformas também se beneficiaram do advento dos podcasts, ganhando popularidade. Ao perceber que a mídia se tornara popular, as plataformas, caracterizadas também como players, agregadores e aplicativos para hospedagem, distribuição e download de arquivos de áudio, tiveram todo interesse em investir nesse tipo de conteúdo, o que as levou a aumentarem seus alcances. Em uma pesquisa realizada no Google Trends, de 2017 a 2019, as plataformas de maior alcance e popularidade no Brasil são Spotify, Deezer, iTunes/Apple Podcasts e Google Podcasts (SANTOS, 2020).

No Brasil, o primeiro podcast a ser lançado foi o Digital Minds. Criado em 2014, o programa foi desenvolvido a partir do desejo de seu idealizador, Danilo Medeiros, de diferenciar seu blog dos demais. Ainda em 2004 foram produzidos os podcasts de Gui Leite, Perhappiness e Código Livre (LUIZ; ASSIS, 2010). O país também organiza premiações dirigidas especificamente ao podcast e desenvolve pesquisas sobre os ouvintes no Brasil. Em 2008 foi instituída a PodPesquisa, uma iniciativa da Associação Brasileira de Podcasters (ABPod), com o objetivo de conhecer mais sobre o universo do ouvinte de podcast no Brasil e subsidiar os produtores.

A forma de distribuição direta e atemporal é uma das diferenças do podcast para o rádio, assim como o consumo de informações de acordo com a transmissão. As rádios possuem uma grade de programação linear com programas ao vivo na maioria das vezes, enquanto o podcast é consumido necessariamente sob demanda. Um diferencial do podcast é o baixo custo de produção. Basta um computador acoplado a um microfone apropriado e um software instalado para gravação e edição do áudio. As diferenças não tornam uma mídia melhor do que a outra. Elas atendem a necessidades particulares do ouvinte e podem, inclusive, se complementar (PICARDI; REGINA, 2008).

Os podcasts, que já surgiram na segunda geração da internet (Web 2.0), apresentam possibilidades de produção descentralizada e interatividade. Programas dessa natureza são produzidos em grande parte de forma voluntária e têm um viés ativista, com liberdade dos produtores para defender posições como, recentemente, a valorização das universidades e da ciência. Eles buscam despertar a atenção de ouvintes que querem se aprofundar em assuntos temáticos (MARQUES, 2019). 
Segundo Picardi e Regina (2008) e Dantas-Queiroz, Wentzel e Queiroz (2018), o podcast tem se mostrado uma poderosa ferramenta para a divulgação científica. Cabe destacar que novos modelos de divulgação científica vêm enfatizando o papel que o campo tem de promover ações que vão além da transmissão de informação descontextualizada (BROSSARD; LEWENSTEIN, 2021). Em um 'modelo contextual', que privilegia o diálogo com a sociedade, essas ações devem privilegiar a relevância da informação para os diferentes públicos, e permitir que eles se engajem em camadas de interação com o campo científico (MILLER, 2001). Tão importante quanto o conteúdo a ser divulgado, são as estratégias de construção desse conteúdo com a sociedade, como forma de engajá-la no debate científico. Neste sentido, Castelfranchi e Fernandes (2015) sintetizam, na ideia de uma cidadania tecnocientífica, a emergência de espaços, ações e práticas que, em um compartilhamento do poder, favorecem uma maior atuação das pessoas nas decisões e controvérsias do campo científico, que, por influenciarem todos, não devem se restringir a pequenos grupos 'técnicos'.

Portanto, a divulgação cientifica, dentro da compreensão contemporânea de seu campo, é uma atividade que vai muito além da "tradução" ou "simplificação" de conceitos científicos para o grande público, como ainda permanece no senso comum do campo científico. Segundo Horst, Davies e Irwin (2017), podemos entender divulgação científica como "ações organizadas, explícitas e intencionais que visam comunicar conhecimento, metodologias, processos ou práticas científicas em contextos em que não-cientistas são uma parte reconhecida do público." (HORST; DAVIES; IRWIN, 2017, p. 883, tradução nossa). Logo, podcasts de divulgação científica se caracterizam por ter um conteúdo que fale sobre resultados da ciência, sobre cientistas, sobre o processo da ciência ou mesmo sobre a política e prática científica.

Sua facilidade de produção permite que cientistas possam se apropriar e produzir rapidamente conteúdo para dialogar diretamente com o público. Além disso, é uma ferramenta favorável para mesclar entretenimento com discussão de temas científicos. Por se basear em áudio, traz, para o produto, uma sensação de intimidade, como se os produtores do áudio, estivessem ali, junto com os ouvintes, falando para eles (BERRY, 2006). Diferente do rádio, o ouvinte tem a oportunidade de escolher e selecionar o que quer ouvir criando um engajamento do público no processo. Por fim, o podcast tem também um grande potencial para estimular conversas sobre ciência em outras plataformas, de forma a permitir aprofundamento e diálogo sobre os temas propostos (BIRCH; WEITKAMP, 2010, PICARDI; REGINA, 2008). Pela sua versatilidade, o podcast permite incorporar vozes de minorias ao seu processo de desenvolvimento e produção que, muitas vezes, são silenciadas em outros meios (FANTINI; BUIST, 2021). Dessa forma, seu processo de produção facilita um maior engajamento social (BROSSARD; LEWENSTEIN, 2021).

Os resultados da PodPesquisa (ABPOD, 2020), realizada em 2019 com mais de 16 mil ouvintes, apontaram que majoritariamente o público que consome podcast é masculino (72\%). Mais da metade tem entre 20 e 29 anos, seguido da faixa entre 30 e 39 anos (31\%). Sete em cada dez estão cursando ou concluíram nível superior e 19\% têm pós-graduação. De acordo com a mesma pesquisa, dos 20 programas mais ouvidos no país, dois são de divulgação científica: SciCast e Naruhodo. Na comparação entre os anos de 2018 e 2019, o interesse pela ciência teve um crescimento de $9 \%$, um dos maiores do período, sendo declarado por 52,3\% dos ouvintes, o terceiro maior percentual da pesquisa.

Outra pesquisa relacionada aos podcasts foi a elaborada pelo Instituto Brasileiro de Opinião Pública e Estatística (Ibope) e realizada em 2019. Duas mil pessoas foram entrevistadas em um curto período de tempo e o resultado demonstrou que o perfil do ouvinte coincide com o resultado obtido na PodPesquisa: um público masculino e jovem mais interessado na mídia, cerca de $45 \%$ e $47 \%$ dos entrevistados, respectivamente; a frequência com que ouvem (43\% não costuma ouvir programas com regularidade, mas $19 \%$ do total ouve podcasts três vezes ou mais por semana); o equipamento mais utilizado é o celular (75\% 
ouve por ele); e as plataformas mais utilizadas para acessar a mídia são o YouTube (42\%) e o Spotify (32\%) (PACETE, 2019).

Gums et al. (2019) ressaltam alguns outros resultados da PodPesquisa de 2018: 52,3\% de respondentes afirmam consumir conteúdos de ciência, o que, segundo os autores da pesquisa exploratória, embasa a hipótese de que ciência é um dos temas mais ouvidos no Brasil. Outro destaque é o viés formativo do consumo de podcasts brasileiros, em que 80,7\% ouvem para aprender coisas novas e 79,9\% para se informar. Diante desses dados, os autores entendem que a divulgação de informações científicas é uma pauta importante da comunidade brasileira e que o podcast é uma ferramenta para legitimação da produção científica. Bueno e Fonseca (2020) ao analisarem 88 podcasts de divulgação científica percebem a relevância de podcasts produzidos de forma independente por cientista e divulgadores da ciência, sendo a maioria de conteúdo multitemático.

No âmbito internacional, vale destacar a pesquisa publicada por Mackenzie (2019) em que foi analisada a produção global de podcasts de ciências em língua inglesa, de 2004 a 2018, cujo crescimento se manteve linear entre 2004 e 2010 e eclodiu entre 2010 e 2018. Apesar de mapear podcasts de ciência em geral, incluindo aqueles de divulgação científica e os podcasts que têm outros cientistas como audiência definida, o autor aponta que, em geral, mesmo esse estilo de podcast de ciência é consumido pelo grande público. Em geral, uma das marcas da produção é a irregularidade do lançamento de episódios, uma vez que 57\% dos canais podem ser considerados irregulares, ou seja, sem um período de lançamento fixo como semanal, mensal etc. Além disso, apenas $46 \%$ foram considerados ativos, ou seja, tinham lançado algum episódio nos três meses anteriores ao levantamento (MACKENZIE, 2019).

Foram identificados 952 podcasts de ciências disponíveis em inglês, dos quais $65 \%$ foram apresentados por cientistas e $77 \%$ destinados ao público em geral. Outro dado é que a maior parte dos principais assuntos dessas produções estavam relacionados à ciência, dando destaque à biologia e física em detrimento da química, por exemplo; 34\% não era dedicada a esse objeto, uma vez que o estudo considerou apenas podcasts relacionados às ciências naturais. $\mathrm{E}$, por fim, $62 \%$ dos podcasts de ciências apareciam afiliados a uma organização que produziu uma média muito maior de episódios do que os produtores independentes. Em geral, os podcasts independentes apresentam uma maior irregularidade de produção, provavelmente devido a uma falta de uma estrutura profissional por trás (MACKENZIE, 2019).

Essa pesquisa forneceu o primeiro cenário imediato de como os podcasts de ciências estavam sendo usados para comunicar a ciência ao público em geral em todo o mundo, num cenário onde há uma produção muito escassa de análises sobre podcasts, em particular sobre os podcasts de divulgação científica (MACKENZIE, 2019). Mackenzie (2019) considera que existe um grande interesse em podcasts por parte de divulgadores científicos, em especial cientistas profissionais, que produzem os episódios a partir de uma atividade de extensão, pela simplicidade de produção e efetividade da mídia. Segundo o autor é uma mídia de longo alcance, com possibilidades de uso de uma linguagem mais coloquial e até mesmo utilizando o humor, o que traz uma maior aceitação na audiência (MACKENZIE, 2019).

Neste artigo foram levantados os formatos dos podcasts dedicados à popularização da ciência disponíveis hoje no Brasil. Considerando a escassez de literatura na área, que é ainda mais notável no Brasil, esse estudo busca mapear e compreender a produção de podcasts dentro do cenário brasileiro. A classificação dos diferentes programas oferece ao público a oportunidade de escolher aquele que mais se adequa ao seu gosto. Dessa foram os podcasts de divulgação científica brasileiros foram mapeados e classificados segundo seus produtores, formato de programa e assunto dominante. Dessa forma espera-se uma imersão nesse mundo ainda pouco explorado para compreender sua dinâmica e suas especificidades. 


\section{METODOLOGIA}

A pesquisa aqui apresentada tem caráter qualiquantitativo, por mapear os podcasts de divulgação científica no contexto brasileiro, classificar esses canais, analisar os formatos mais comuns entre os mais escutados pela comunidade de assinantes, e, com um viés etnográfico digital, refletir sobre a cultura, os hábitos dos ouvintes e as interações sociais no ciberespaço com a apropriação da internet tanto por quem produz conteúdo quanto por quem os consome (POLIVANOV, 2013).

Ao se referir à linguagem radiofônica, Barbosa Filho (2003) afirma que ela se encaixa nos diversos gêneros encontrados no rádio e utiliza o termo gênero para definir tipologias específicas que direcionam a mensagem de acordo com o interesse do público. Entre os gêneros, ele destaca: jornalístico; educativoculturais; entretenimento; publicitário; serviço; e especiais. A esses gêneros radiofônicos, citados por Barbosa Filho, é dado o nome de formato de produção de podcasts nesta pesquisa.

Nosso trabalho buscou identificar formatos que atendiam mais ao interesse de ouvintes de podcast, que formam uma rede com um jeito próprio de interagir na podosfera, ou seja, na comunidade que se organiza em torno dos podcasts. Segundo Freire (2017), podemos entender a podosfera como:

um cenário educativamente rico, constituído como mote para reunião de Sujeitos que, compartilhando um gosto em comum por determinado tema abordado em podcast, acabam exercitando um diálogo educacional nas seções de comentários dos blogs das produções e nos fóruns de redes sociais aglutinadores da audiência de um programa, além do contato direto com os produtores das realizações (p. 64).

Não havia intenção de estudar comportamentos e hábitos de indivíduos nem de comunidades específicas na internet, por tratar-se de pesquisa exploratória cujo objetivo é proporcionar uma visão geral. Porém, a pesquisa traz esses dados de forma subjetiva, como consequência da manifestação do interesse por um formato ou outro de programa. Por essa razão, ela tem um pouco do viés etnográfico (digital ou virtual). Essa informação ajuda a traçar um perfil de quem busca conteúdo por meio dos arquivos de áudio e estabelece a forma como o ouvinte se relaciona com os produtos e os produtores ouvidos.

A pesquisa exploratória tem o caráter de se aproximar mais do objeto estudado, trazendo-o do campo mais genérico para uma sistematização, o que ajuda no aprofundamento posterior da investigação do tema (GIL, 2008). E, neste sentido, o trabalho cumpre essa função apresentando os formatos de podcast como possíveis vantagens na escolha do indivíduo para se entreter e se informar. Uma outra pesquisa poderá dar conta de qualificar melhor esse dado, investigando a fundo os formatos e perfis de ouvintes de cada um deles.

\section{Levantamento exploratório dos programas}

A primeira fase da pesquisa consistiu em buscar diretamente nos navegadores de internet e nos agregadores de podcasts de divulgação científica que se encaixavam no critério da pesquisa proposta. Foi definido que, no universo de podcasts de divulgação científica brasileiros, o estudo iria se concentrar apenas nas produções brasileiras e em todos os programas que incluíssem em sua descrição as seguintes palavras-chave: divulgação científica, ciência, cientista, descoberta científica, popularização da ciência ou pesquisa científica ou a palavra ciência nas tags.

Os programas selecionados pelas palavras-chave tiveram seu conteúdo validado a partir da definição de divulgação científica de Horst, Davies e Irwin (2017). Uma amostra do podcast foi escutada para verificar se os assuntos abordados nos programas eram relacionados com ciência, ou seja, tinham como intenção explícita apresentar resultados da ciência, apresentar cientistas, discutir a prática científica ou mesmo as questões políticas ligadas à ciência. Por ciência, ao contrário de levantamentos internacionais (MACKENZIE, 2019) que focam apenas nas ciências naturais, ficam compreendidos todos os ramos da 
ciência reconhecidos pelo CNPq, ou seja, Ciências Exatas e da Terra, Ciências Biológicas, Engenharias, Ciências da Saúde, Ciências Agrárias, Ciências Sociais Aplicadas, Ciências Humanas, Linguísticas, Letras e Artes. O critério fundamental é ter explicitamente a intenção de dialogar sobre o campo enquanto ciência. Dos 73 canais previamente encontrados com as palavras-chave mencionadas, apenas um foi descartado por conter conteúdo da área da educação física, não com o objetivo de divulgação científica, mas de práticas de bem-estar. Não foram encontrados podcasts que tivessem, como foco de audiência, outros cientistas.

O levantamento exploratório foi realizado em novembro de 2019 nos agregadores de podcast mais populares, como o Spotify, Deezer, Anchor e Google Podcast (esses foram os agregadores que apareceram durante a pesquisa dos programas pela internet). A busca em vários agregadores ajuda a diminuir a influência do algoritmo de busca de cada um. Cabe destacar que o levantamento foi feito antes do início da pandemia de covid-19, quando houve um grande aumento na procura por informações relacionadas à ciência (SILVA; D'ANDREA, 2020). Foram identificados 72 podcasts que se encaixavam no recorte definido e criada uma lista prévia. Os podcasts foram listados em uma tabela no programa Word juntamente com as informações sobre as palavras que os definiam, a plataforma em que foram encontrados e seus produtores. A lista completa pode ser encontrada em Figueira (2020). Essa tabela consiste no levantamento que serviu de base para começar a ouvir os programas.

\section{Coleta de dados: classificação dos podcasts}

O primeiro passo dessa fase foi a pesquisa de formatos de podcasts existentes. A pesquisa foi feita pela internet diretamente nos agregadores ou utilizando a busca no Google. Em seguida, começaram as escutas dos programas. À medida que os episódios eram ouvidos, os formatos e as observações sobre o conteúdo eram descritos.

A partir do levantamento organizado, os programas foram ouvidos na ordem em que apareciam na listagem. Se determinou que seriam escutados três episódios de cada podcast, entendendo que isso seria necessário para poder fazer comparações dentro da mesma produção. Por conta do número elevado de podcasts, a pesquisa se concentrou apenas nos podcasts mais antigos, mais populares e com regularidade na publicação. A planilha de classificação foi organizada por categorias. Cada episódio de um podcast foi classificado de acordo com sua descrição, duração, área do conhecimento, produção, seus participantes e seu formato.

A descrição dos formatos pode ser encontrada nos agregadores, o que dependia do podcast. A responsabilidade por essa descrição, entre outras informações relacionadas ao podcast, é de quem o produz. Por isso, nem sempre é possível encontrá-la facilmente. E mesmo quando isso ocorre, é comum nos depararmos com outros formatos do mesmo programa ao ouvi-lo. Tal fato nos fez perceber que a descrição, quando existe, muitas vezes não dá conta de explicar a forma como o conteúdo será apresentado.

A classificação dos formatos neste trabalho foi o somatório dos textos descritivos em plataformas distintas e a observação do que foi ouvido. Não existe um consenso sobre os possíveis formatos para podcast (SILVA; SANTOS, 2020). A classificação adotada aqui seguiu as próprias designações do próprio campo, bem como a observação de viés etnográfico dos autores, que construíram os formatos como proposta para compreender a produção de podcast voltados a divulgação científica.

A partir principalmente da escuta dos programas foi possível compreender os formatos e descrevê-los, conforme é demonstrado no Quadro 1, baseado também no que já se conhece sobre formatos oriundos do rádio. A mídia podcast, apesar de ter diferenças claras do meio de comunicação rádio, como já descrito no referencial teórico da pesquisa aqui apresentada, se apropriou de muitos aspectos da forma de produção radiofônica. 


\section{Quadro 1-Descrição dos formatos}

\begin{tabular}{|c|c|}
\hline FORMATO & DESCRIÇÃO \\
\hline $\begin{array}{l}\text { Bate-papo (mesacast } \\
\text { ou polifônico) }\end{array}$ & $\begin{array}{l}\text { programa para conversar com amigos ou com a participação de convidados sobre algo que } \\
\text { se entende ou de que gosta. Pode ter o tom engraçado, descontraído e tratar assuntos } \\
\text { sérios com leveza. }\end{array}$ \\
\hline Storytelling & $\begin{array}{l}\text { forma de roteiro, um estilo de escrita muito usado em jornalismo, crônicas etc. Em um } \\
\text { podcast storytelling você vai ouvir (ou contar) uma história. O storytelling pode ser } \\
\text { jornalístico, um audiodrama ou apenas alguém falando sobre algo. }\end{array}$ \\
\hline Educacional & $\begin{array}{l}\text { pode ser tanto um complemento de aula ou aulas e cursos inteiros ou palestras inteiras. } \\
\text { Existem vários programas de podcasts de EaD (ensino a distância), desde que sejam aulas } \\
\text { que não exijam muita informação visual. }\end{array}$ \\
\hline Programas de rádio & $\begin{array}{l}\text { trechos de programas de rádio distribuídos como podcast ou podcasts que parecem ser } \\
\text { programas de rádio. }\end{array}$ \\
\hline Podcast solo & $\begin{array}{l}\text { basicamente você e o ouvinte conversando, compartilhando seus pensamentos sobre } \\
\text { qualquer tópico do podcast. O podcast solo é ideal para você compartilhar sua tendência } \\
\text { única no mundo. }\end{array}$ \\
\hline Entrevista podcast & $\begin{array}{l}\text { formato de pergunta e resposta na voz do especialista sobre o tema tratado no episódio. } 0 \\
\text { convidado pode participar das seguintes formas: } \\
\text { telefone - grave a entrevista em seu smartphone usando um aplicativo de gravação de } \\
\text { chamadas. Será necessário sincronizar os dados com o computador para a edição (a menos } \\
\text { que se tenha as ferramentas para editar e carregar no telefone); } \\
\text { Skype - na falta de um smartphone, se utiliza o Skype para ligar para outras contas e } \\
\text { telefones. Com a ferramenta de gravação de chamadas Skype Gravador é possível gravar } \\
\text { chamadas por Skype em arquivos MP3. O áudio capturado poderá ser incluído, depois, no } \\
\text { podcast. }\end{array}$ \\
\hline Show multi-Host & $\begin{array}{l}\text { variadas vozes e opiniões participam ao mesmo tempo do programa. Muitos podcasters } \\
\text { usam essa opção para começar. }\end{array}$ \\
\hline Mesa redonda & um único host apresenta três ou mais convidados para discutir um tópico. \\
\hline Revista de áudio & $\begin{array}{l}\text { mistura eclética de notícias, entrevistas, discussões e algumas piadas. Pode ter um único } \\
\text { host ou vários hosts. }\end{array}$ \\
\hline Informativo & $\begin{array}{l}\text { produção com linguagem direta e objetiva para informar o leitor sobre determinado } \\
\text { assunto. }\end{array}$ \\
\hline $\begin{array}{l}\text { Comentários } \\
\text { e perguntas e } \\
\text { respostas }\end{array}$ & leitura durante o programa de comentários e respostas aos e-mails enviados por ouvintes. \\
\hline Tutorial & ensina o passo a passo do funcionamento de algo. \\
\hline Drops/pílulas & pequenos informes com dicas sobre determinado tema. \\
\hline
\end{tabular}

Fonte: elaboração dos autores.

\section{Análise dos dados}

Na terceira fase do trabalho, partiu-se para a análise dos dados coletados. Foi um estudo quantitativo, mas também qualitativo, na medida em que foram observados conteúdos e interações sociais. As categorias foram área do conhecimento, produtor e formato. A descrição dos resultados contemplou outros dados que não estavam diretamente relacionados ao formato, mas tinham relevância no processo de produção dos programas e fizeram parte de uma análise qualitativa. Podemos citar a regularidade 
na produção e na publicação dos episódios, o apoio recebido para produção e produtores de conteúdo comuns para podcasts diferentes.

\section{RESULTADOS E DISCUSSÃO}

Como apontado anteriormente, a pesquisa teve por objetivo identificar formatos distintos de podcasts brasileiros de divulgação científica. Inicialmente foram levantados 72 podcasts cujas palavras-chave traziam nomes como divulgação científica, ciência, publicação científica, popularização da ciência, cientista e pesquisa científica ou a palavra ciência em suas tags. No entanto, no começo da coleta de dados, ou seja, quando os podcasts começaram a ser escutados a relação diminuiu para 69, como descrito nos parágrafos a seguir.

Em um dos casos se percebeu que a descrição 'divulgação científica' do podcast não necessariamente tratava do campo do conhecimento. Ao ouvir o Isulbracast foi constatado que o conteúdo se resumia a negócios nas áreas de educação física, saúde e nutrição. Ele é descrito como "Projeto voltado para a divulgação científica. Discussão de temas que sejam transversais ao mundo científico” (MENEZES JÚNIOR, [2019?]). Isso nos fez perceber que a descrição não é suficiente para categorizar a área. É preciso escutar o programa de modo a entender do que ele realmente trata.

Outro podcast retirado da lista foi o Caranguejo Samurai, não por seu conteúdo, mas porque os episódios não foram mais encontrados, além de um gravado com o nome Teste. Faltam referências na internet sobre a mídia, inclusive sobre o produtor do programa. E o último eliminado do levantamento foi o Nerdologia por não ser um podcast, e sim um programa no YouTube sobre divulgação científica. No momento da pesquisa, ele foi encontrado em um site especializado em podcast e, por essa razão, se imaginou tratar de um programa da mesma natureza.

A fase de coleta de dados é fundamental, pois permite a real visão do objeto estudado. A partir de um filtro que se faz no levantamento prévio de informações, torna-se possível a adequação do universo a ser pesquisado. Além da exclusão dos três podcasts, é necessário destacar outra questão experimentada durante a coleta: a observação de que a produção de um podcast pode ser interrompida rapidamente por razões diversas depois de poucos episódios publicados. Exemplos disso são o AgDC e o Minutos da Ciência que, mesmo só encontrando dois episódios publicados de cada, foram mantidos no levantamento e analisados por seus conteúdos. Vale lembrar que na metodologia desse trabalho foi definido escutar três episódios de cada podcast pesquisado, para facilitar a identificação do formato proposto pelos produtores e entender qualquer variação nesse formato.

Do total de 69 podcasts, como descrito anteriormente, foram selecionados 37 para este artigo. A necessidade de reduzir o número de programas fez com que se definissem critérios para a escolha dos podcasts que seriam ouvidos. Foram selecionados os mais populares, os que tinham regularidade na publicação e os mais longevos. Dessa forma, o resultado apresentado representa mais de 50\% do levantamento total da pesquisa. Os podcasts selecionados estão na Tabela 1. 
Tabela 1 - Nomes dos podcasts analisados e quantidade de episódios analisados por podcast

Nome do podcast

37 Graus

60 Hertz Podcast

AgDC - Agência de Divulgação Científica e Comunicação do Instituto de Biociências de Botucatu (IBB) - Unesp

Alô, Ciência?

Bug Bites Podcast

ClickCiência

Coffee break dos Astrotubers

Contrafactual (E se...)

Dragões de Garagem

Ensinecast

Fala, Cientista!

Fiocruz no $\mathrm{Ar}$

FIZencadeando Leituras

Fronteiras da Ciência

História FM

Larvas Incendiadas

Microbiando

Minutos de Ciência

Naruhodo

NeuroPod

Oxigênio

O Nicho Podcast

Paideia - Cultura e Ciência

Papo com Cientista

PlantaCiência

PodScience

Projeto Conexão

Qubits \& Quasares

Rock com Ciência

SciCast

Serendip - cientistas infalíveis

Somos Cintia

Spin de Notícias

Temacast

Teoria em Prosa: Saberes em Comunicação

Rinite Cósmica

UFABC Divulga Ciência

Total de episódios
Quantidade de episódios analisados

3

3

2

3

3

3

3

3

3

3

3

3

3

3

3

3

3

2

3

3

3

3

3

3

3

3

3

3

3

3 (incluindo SciKids programa infantil do SciCast)

3

3

3

3

3

3

3

109

Fonte: elaboração dos autores. 
Foram ouvidos 109 episódios, três de cada um dos 37 podcasts (com exceção de dois programas que só tinham dois episódios cada). A escolha dos episódios teve por base as publicações mais recentes. Eventualmente, houve necessidade de identificar episódios específicos de divulgação científica que não estavam entre as últimas publicações. Nesse momento, os formatos eram observados. Existem alguns formatos, cada um dando o ritmo do programa, que podem ser mais atordoantes por terem muitas pessoas falando ao mesmo tempo (polifônico) ou mais calmos com um narrador contando uma história. A escolha do ouvinte vai depender do estilo pessoal, mas a habilidade do apresentador, seja qual for o formato, conta muito também quando se quer conquistar atenção.

Antes de passarmos para a explicação a seguir, é importante destacar que há podcasts que têm um único programa e os que têm o programa 'carro-chefe' e outros de menor destaque. Chamamos aqui de produto e subproduto (ou spin off) de um podcast, respectivamente. Este é o caso do Rinite Cósmica com o subproduto Miojo, que tem a duração em torno de cinco minutos, e Espirro, produto com maior duração no formato mesacast em que os hosts conversam entre si.

No que diz respeito aos formatos dos podcasts, foram percebidas duas possibilidades de variações entre os programas escutados. Uma delas é a mudança de formato do mesmo produto, ou seja, do mesmo programa. É possível ter o 'carro-chefe' apresentado de formas diferentes em cada episódio. Em outros casos, o que se percebeu foi a variação de formatos de um podcast em seus diferentes programas (nos subprodutos).

O AgDC tem formatos diferentes em episódios do mesmo programa. Encontramos um episódio inteiro de palestra com o ex-diretor do Instituto Nacional de Pesquisas Espaciais (Inpe), Ricardo Galvão, gravado no auditório de uma universidade com os alunos e outro com seis hosts apresentando um tema diferente em um bate-papo. O Bug Bites também apresentou variações da mesma natureza. Dos três ouvidos para a pesquisa, dois foram entrevistas e um foi bate-papo entre os apresentadores (hosts) com quadro de variedades. E para dar continuidade à lista de podcasts que mesclam formatos no mesmo produto, o Larvas Incendiadas tem episódio de contação de história (storytelling), apesar de ser um podcast de entrevista.

Existe também o caso em que o podcast tem três subprodutos, cada um com formato específico. O Nicho Podcast publica o Nicho Drops, uma entrevista com um pesquisador para tratar de um artigo que ele tenha publicado; o Micronicho é um programa em que são explicados conceitos biológicos; e o Metanicho, uma mesa redonda em que se discute com um convidado o papel do biólogo em áreas distintas da ciência, do mercado de trabalho e da sociedade.

Também como resultado da pesquisa, algo muito comum e interessante observado nos podcasts que têm plataforma própria e, em alguns casos, no descritivo dos episódios nos agregadores em que são publicados, independentemente do formato do programa, é a indicação de referências pesquisadas, links com sugestões de vídeos, livros, artigos científicos e matérias sobre o tema, roteiros na íntegra do episódio, descrição do tema, que pode ser sucinta ou extensa, e ficha técnica. Há uma convergência de mídias que, além de trazer credibilidade ao podcast (do produto e subproduto quando existe), enriquece o conteúdo com informações complementares, que permitem ao ouvinte o aprofundamento do tema. Um dos diferenciais do podcasts em relação à outras mídias, como o rádio, é que por estar abrigado nativamente no ambiente da internet, permite uma convergência de mídias e uso da própria rede de forma a interagir com seus públicos (BIRCH; WEITKAMP, 2010; MACKENZIE, 2019).

Os textos escritos encontrados em sites ou agregadores facilitaram muito a coleta de dados para o preenchimento da tabela de classificação dos podcasts durante o trabalho. Alô, Ciência?, História FM, 60 Hertz Podcast, Minutos de Ciência, Somos Cintia são alguns exemplos, mas a maioria traz informações adicionais para tornar a experiência do ouvinte, que podemos chamar também de assinantes, mais completa e multimídia. 
Além das variações citadas anteriormente, temos ainda áreas do conhecimento distintas entre os podcasts pesquisados, o que no recorte desse estudo dá alguma dimensão dos campos explorados pela ferramenta de comunicação para divulgar a ciência.

Existem podcasts específicos de uma área como o Dragões de Garagem sobre biologia e outros que transitam por áreas distintas com foco na temática. O Fala, Cientista! é um exemplo que trata de temas da biologia, assim como pesquisas na área do direito, o que demostra a multidisciplinaridade de alguns projetos de podcast. No gráfico abaixo, são descritas as áreas mais encontradas nos podcasts pesquisados (Figura 1).

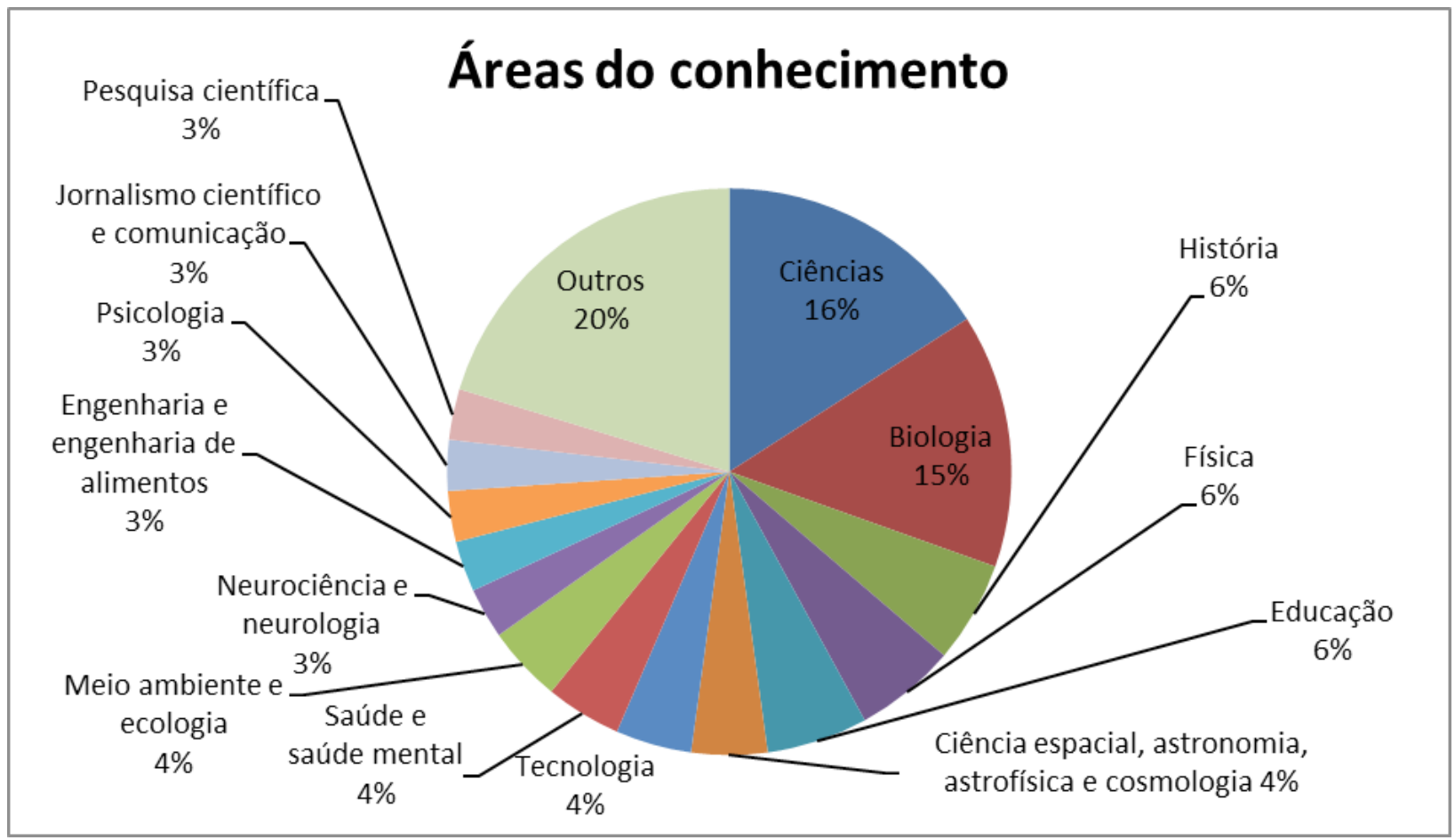

Figura 1 - Distribuição por área do conhecimento

Fonte: elaboração dos autores.

Ainda tratando de formatos, objeto do presente trabalho, o bate-papo ou mesacast tem uma característica dinâmica que não impõe barreiras (a não ser a falta de tecnologia) em sua apresentação. O bate-papo entre o apresentador (host) e os convidados, ou apenas entre hosts, pode acontecer em tempo real com os participantes situados em locais diferentes. Não necessariamente as pessoas do episódio estão juntas presencialmente, sequer estão no mesmo estado ou país. Essa característica se mostrou natural e recorrente.

Outro aspecto do mesacast é o fato de nem sempre todos os hosts participarem do mesmo episódio. Isso pode acontecer no formato multi-host, em que os apresentadores são muitos e não são fixos, com exceção de um ou dois, e por essa razão se faz um rodízio entre eles nos episódios, e no formato bate papo com poucos apresentadores, todos fixos, em que um ou mais pode ficar de fora do episódio pontualmente.

Vale destacar que basicamente todos os podcasts, independentemente de seu formato, iniciam o programa com recados, principalmente os independentes, para pedido de apoio financeiro ou de curtidas e comentários, esses últimos para elevar seus índices junto às plataformas de publicação. Alguns podcasts no formato mesacast, além dos lembretes iniciais, começam o episódio com uma breve narração sobre o tema destacado do início do programa propriamente dito.

A flexibilidade na produção de um podcast se mostrou outra característica presente. Formato, periodicidade e duração variam com certa frequência. O que se percebeu foi a dificuldade, muitas vezes, 
para se produzir os episódios e manter a regularidade ideal. As razões podem ser diversas. Em alguns casos, pode ser a dificuldade de manter uma produção mais complexa, a depender do formato do podcast. Um storytelling (contação de história) necessita de uma roteirização muito bem-feita para dar cadência ao texto que será lido. É um trabalho que exige produção mais dedicada e cuidadosa. Em outros, fica clara a dependência de financiamento, como o 37 Graus, que recebeu verba do Instituto Serrapilheira para produzir duas temporadas. A opção de se produzir por temporada também pode ser para baratear custos, otimizando recursos em pouco tempo de produção.

Quanto à duração, pode variar de acordo com o formato ou com a dimensão do tema. Uma entrevista tende a ter, em média, duração entre 15 e 50 minutos. Já um mesacast pode chegar a episódios que variam muito de duração de acordo com o assunto. Alguns episódios têm 90 minutos e outros, do mesmo programa, podem chegar a quatro horas. E tem ainda os podcasts que só dão dicas (dropcast) e duram cerca de cinco minutos.

Essa pesquisa mostrou um universo rico de possibilidades nos formatos dos programas, que incluem ainda opções para faixas etárias distintas. O SciCast é um exemplo com seu spin-off (subproduto) SciKids voltado para crianças. O host responde perguntas enviadas por crianças de idades diversas sobre um tema do SciCast que tenha repercutido muito. $\mathrm{O}$ formato Perguntas e Respostas quase não foi encontrado nessa pesquisa, a não ser como um quadro dentro de um programa. Geralmente, na resposta aos e-mails enviados pelos ouvintes.

$\mathrm{Na}$ fase de coleta de dados, em que os podcasts foram escutados, foi observado quem produzia o conteúdo. A maioria dos podcasts que fizeram parte do levantamento desse estudo foram produzidos por universidades. Em seguida, aparecem as produções independentes e as produtoras de conteúdo, como a B9 Company, Megafono, Deviante, entre outras, que acabam por produzir mais de um podcast. Os dados podem ser vistos em um gráfico a seguir (Figura 2).

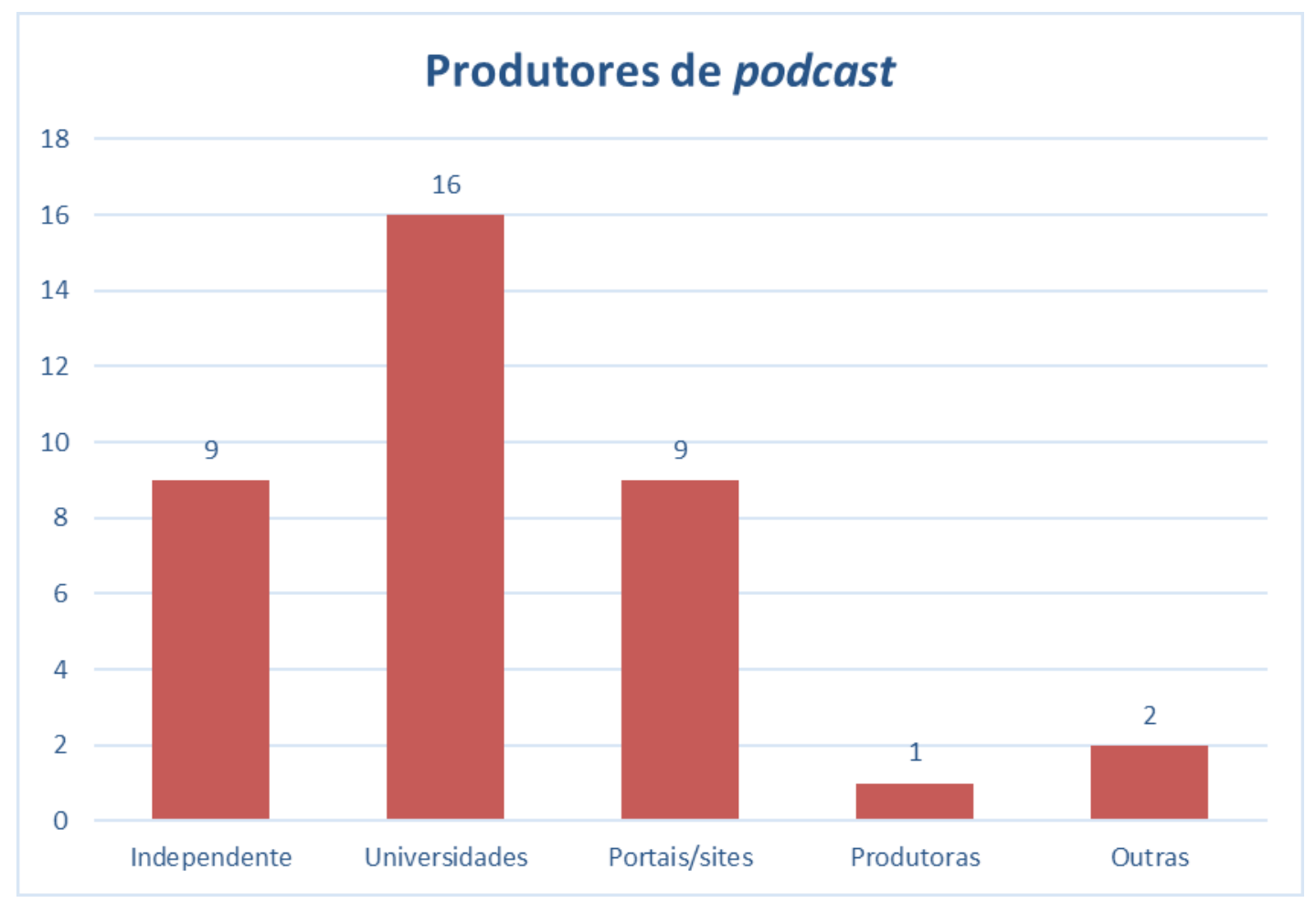

Figura 2 - Distribuição por produtor de conteúdo Fonte: elaboração dos autores. 
Independentemente de quem produz o podcast ou do seu formato, o que se percebe é a maneira solta, mais livre de se expressar. A coloquialidade é uma marca nos podcasts, a busca da espontaneidade na forma de explicar os assuntos, o que torna a ferramenta de comunicação apropriada para a popularização da ciência. Merzagora (2004) já havia sinalizado que a mídia sonora possui uma linguagem mais coloquial e que aproxima a audiência do produtor do conteúdo, ajudando a quebrar estereótipos. Como já era apontado por Bueno (2010), a divulgação científica deve decodificar e recodificar discursos que se aproximem das características discursivas de sua audiência. Lima e Giordan (2021) argumentam a favor da divulgação científica como gênero discursivo, afastando-se da interpretação da divulgação científica como reformulação discursiva. Uma das características desse discurso é a inclusão de índices de objetividade e subjetividade, como estratégia de aproximação da sua audiência e a inclusão do produtor do discurso como parte integrante dele, característica que é apropriada pelos podcasts.

Por fim, pôde-se notar que os formatos mais presentes entre os podcasts e seus episódios ouvidos na pesquisa são o bate-papo (mesacast) e a entrevista. O que tem mais destaque é o formato bate-papo, que aparece em 19 podcasts e 39 episódios da amostra ouvida. É seguido pelo formato entrevista, presente em 12 podcasts e 28 episódios da mesma amostra (Figura 3).

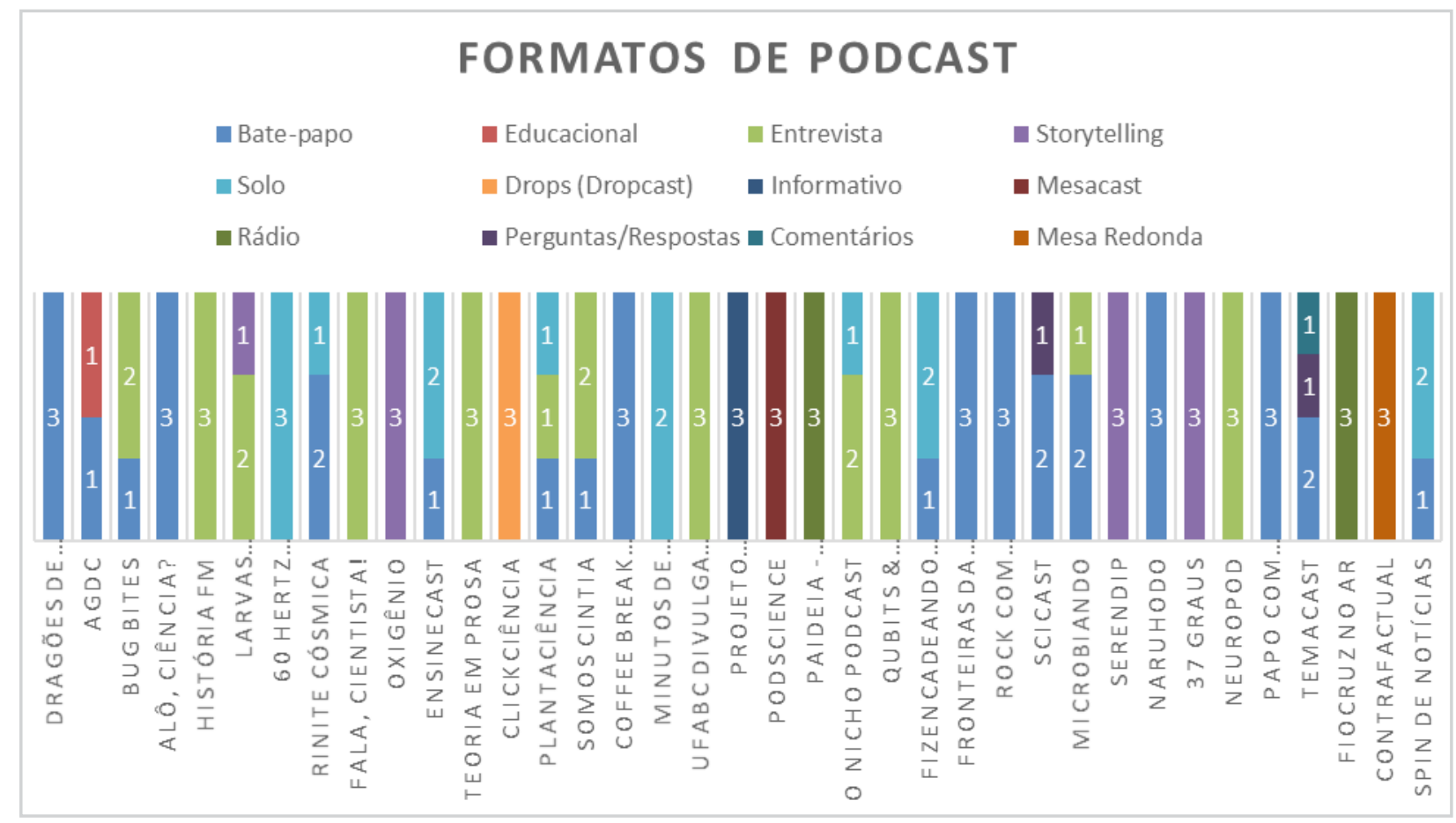

Figura 3 - Distribuição por formato de podcast

Fonte: elaboração dos autores.

Outros estudos também vêm pesquisando os podcasts de forma exploratória. Gums et al. (2019) mapearam 63 podcasts brasileiros de divulgação científica para explorar o cenário de produção desses programas, dentre os quais 21 estão contemplados na pesquisa em pauta. O resultado do trabalho apresentou os pesquisadores majoritariamente na linha de frente das produções, grande parte de forma independente. Os resultados foram aplicados para a produção do podcast Fala, Cientista! por alunos da Universidade Federal do Paraná (UFPR), um dos programas identificados e ouvidos na fase de coleta de dados do atual trabalho. Bueno e Fonseca (2020) analisaram novamente o podcast em uma base de 88 podcasts e chegaram a considerações similares às de Gums et al. (2019).

Nossa pesquisa seguiu um caminho diferente, objetivando explorar os formatos de alguns programas brasileiros de divulgação científica. O 'como fazer' distingue um programa do outro e faz com que os 
conteúdos sejam mais facilmente compreendidos pelos ouvintes. As narrativas também são construídas pela forma de apresentá-las e faz toda diferença no alcance de um podcast e na intenção de disseminar os mais variados conhecimentos.

Como já dito, o resultado da pesquisa mostrou que formatos mais descontraídos, como um bate-papo, são os preferidos para ouvir a qualquer hora do dia. Não necessariamente conversas entre muitas pessoas e de forma confusa - mesacasts com bastante interferência e agitação são populares entre os jovens -, mas a interação espontânea entre apresentadores torna os assuntos discutidos mais interessantes e fluidos.

$\mathrm{Na}$ amostra considerada neste artigo, o maior grupo de podcasts de divulgação científica tem instituições de ensino e pesquisa por trás de suas produções, diferentemente do que apontam Gums et al. (2019) e Fonseca e Bueno (2020). Porém, esse grupo não chega a constituir a maioria dos podcasts que, em geral, têm cientistas independentes, portais ou produtoras por trás. Apesar das universidades investirem em produção de podcast, por meio de seus laboratórios, ainda é fato o grande volume de produções independentes. O que nos leva a pensar que essa pode ser uma das razões para existir uma colaboração mútua na podosfera em que produtores se ajudam fazendo referências aos podcasts de outros.

Outro resultado divergente entre a pesquisa aqui apresentada e a de Gums et al. (2019) diz respeito à área do conhecimento. Enquanto a biologia aparece em $3 \%$ dos podcasts pesquisados por Gums et al. (2019) - sua pesquisa demonstrou interesse maior dos respondentes pelas temáticas relacionadas à tecnologia da informação e às ciências da computação -, este estudo aponta 15\% dos podcasts de divulgação científica sobre biologia. Não apenas em programas específicos, mas a área com frequência está presente em podcasts que tratam de campos diversos. Mas se compararmos os dois estudos, perceberemos critérios metodológicos distintos para a seleção dos podcasts. Na pesquisa ora divulgada, optou-se por delimitar os podcasts de acordo com palavras-chave ou pelas tags, deixando muitos programas de divulgação científica de fora. Já a pesquisa de Gums et al. (2019) trabalhou com uma lista colaborativa construída entre entusiastas do campo.

\section{CONSIDERAÇÕES FINAIS}

O presente trabalho identificou os formatos dos podcasts de divulgação científica a partir de um recorte específico e levantou quais deles são mais produzidos, imaginando que seu objetivo seja o de levar conhecimento científico de maneira inteligível às pessoas. O que se percebeu foi que a ferramenta de comunicação já tem em si vantagens para a adesão do público que quer se informar ou apenas se entreter, como facilidade de acesso, mobilidade e disponibilidade dos arquivos para a escuta sob demanda. Aliado a esse fato, a forma como o tema é apresentado contribui para o interesse pelo conteúdo. Se investe mais em produções com caráter lúdico, de maior espontaneidade entre os participantes, que podem ser apenas os apresentadores ou ter a presença de convidados, pois não desmerecem a importância do tema e envolvem mais o ouvinte. As pessoas aprendem sem perceber.

O desenvolvimento do presente estudo também demonstrou quanto o tema da pesquisa tem potencial para ser mais explorado. Tratar de formatos pode parecer trivial, uma mera questão de escolha, mas quando a pesquisa aponta que a preferência dos ouvintes é pelos programas que têm bate-papo ou entrevista, parece evidenciar o interesse pelo debate, pela interação das pessoas, e isso faz refletir sobre questões comportamentais e culturais tanto de uma sociedade quanto de um meio de que estamos tratando, que é absolutamente digital. Os formatos bate-papo, também conhecido como mesacast, e entrevista propiciam dinamicidade na apresentação, um dos fatores para atrair a atenção do ouvinte, além de dar mais destaque ao tema. O que se observou ainda desse resultado geral da pesquisa foi a importância de uma análise qualitativa mais aprofundada dos dados. 
Alguns outros pontos foram levantados neste artigo, como áreas do conhecimento, produtores, flexibilidade e regularidade das produções. Não se pretendia avançar nessas questões desde o início, mas o que foi observado naturalmente durante a coleta de dados fez parte do conteúdo textual do trabalho. O que se espera é que a pesquisa possa fomentar o interesse pelo estudo dessas outras características próprias da mídia podcast, levando em conta, inclusive, o perfil do público de acordo com os formatos.

\section{REFERÊNCIAS}

ASSOCIAÇÃO BRASILEIRA DE PODCASTERS (ABPOD). Podpesquisa 2019-2020: análise e resultados. [s. l.]: ABPod, [2020]. Disponível em: https://drive.google.com/file/d/14fyrRYmz1QSOCI5DeEhssLQL376EbEUul view. Acesso em: 19 jan. 2022.

BARBOSA FILHO, André. Gêneros radiofônicos: os formatos e os programas em áudio. São Paulo: Paulinas, 2003.

BARTIS, Cris. O perfil da audiência de podcasts no Brasil. Entrevista concedida à Luiz Gustavo Pacete. Meio \& Mensagem, [s. I.], 23 out. 2018. Mídia. Disponível em: https://www.meioemensagem.com.br/home/ midia/2018/10/23/o-perfil-da-audiencia-de-podcasts-no-brasil.html. Acesso em 18 jan. 2022.

BERRY, Richard. Will the iPod kill the radio star? Profiling podcasting as radio. Convergence: the international journal of research into new media technologies, [s. I.], v. 12, n. 2, p. 143-162, 2006. DOI: https://doi.org/10.1177\%2F1354856506066522. Disponível em: https://journals.sagepub.com/doi/ abs/10.1177/1354856506066522. Acesso em: 14 fev. 2022.

BIRCH, Hayley; WEITKAMP, Emma. Podologues: conversations created by science podcasts. New Media \& Society, [s. I.], v. 12, n. 6, p. 889-909, 2010. DOI: https://doi.org/10.1177\%2F1461444809356333. Disponível em: https://journals.sagepub.com/doi/10.1177/1461444809356333. Acesso em: 14 fev. 2022.

BONINI, Tiziano. A "segunda era" do podcasting: reenquadrando o podcasting como um novo meio digital massivo. Radiofonias - Revista de Estudos em Mídia Sonora, Ouro Preto, v. 11, n. 01, p. 13-32, 2020. Disponível em: https://periodicos.ufop.br/radiofonias/article/view/4315. Acesso em: 14 fev. 2022.

BROSSARD, Dominique; LEWENSTEIN, Bruce V. Uma avaliação crítica dos modelos de compreensão pública da ciência: usando a prática para informar a teoria. In: MASSARANI, Luisa; MOREIRA, Ildeu de Castro (ed.). Pesquisa em divulgação científica: textos escolhidos. Rio de Janeiro: Fiocruz/COC, 2021. P. 15-56.

BRÜGGEMANN, Michael; LÖRCHER, Ines; WALTER, Stefanie. Post-normal science communication: exploring the blurring boundaries of science and journalism. Journal of Science Communication, v. 19, n. 2, p. 1-22, 2020. DOI: https://doi.org/10.22323/2.19030202. Disponivel em: https://jcom.sissa.it/archive/19/03/ JCOM_1903_2020_A02. Acesso em: 14 fev. 2022.

BUENO, Leonardo Mendes; FONSECA, André Azevedo. Panorama da divulgação científica brasileira no YouTube e nos podcasts. In: CONGRESSO BRASILEIRO DE CIÊNCIAS DA COMUNICAÇÃO - VIRTUAL, 43., 1-10 dez. 2020, Salvador. Anais [...]. Salvador: Intercom, 2020. P.1-15. Disponível em: https:// portalintercom.org.br/anais/nacional2020/resumos/R15-0698-1.pdf. Acesso em: 14 fev 2022.

BUENO, Wilson Costa. Comunicação cientifica e divulgação científica: aproximações e rupturas conceituais. Informação \& Informação, v. 15, n. 1 esp, p. 1-12, 2010. DOI: http://dx.doi.org/10.5433/19818920.2010v15n1espp1. Disponível em: http://www.uel.br/revistas/uel/index.php/informacao/article/view/6585. Acesso em: 14 fev. 2022.

CASTELFRANCHI, Yurij; FERNANDES, Victor. Teoria crítica da tecnologia e cidadania tecnocientífica: resistência, "insistência" e hacking. Revista de Filosofia Aurora, Curitiba, v. 27, n. 40, p. 67-196, 2015. DOI: https://doi.org/10.7213/aurora.27.040.DS07. Disponivel em: https://periodicos.pucpr.br/aurora/article/view/616. Acesso em: 14 fev. 2022.

DANTAS-QUEIROZ, Marcos V.; WENTZEL, Lia, C. P.; QUEIROZ, Luciano L. Science Communication podcasting in Brazil: the potential and challenges depicted by two podcasts. Anais da Academia Brasileira de Ciências, Rio de Janeiro, v. 90, n. 2, p. 1891-1901, 2018. DOI: https://doi.org/10.1590/00013765201820170431. Disponível em: https://www.scielo.br/j/aabc/a/5H5N4NnbzJCnqhvqRcDzYSM/ abstract/?lang=en. Acesso em: 14 fev. 2022. 
FANTINI, Emanuele; BUIST, Emilie. Searching for the sources of the Nile through a podcast: what did we find?. Journal of Science Communication, [s. I.], v. 20, n. 2, p. 1-13, 2021. DOI: https://doi. org/10.22323/2.20020801. Disponível em: https://jcom.sissa.it/archive/20/02/JCOM_2002_2021_N01. Acesso em: 14 fez. 2022

FIGUEIRA, Ana Cristina Peixoto. Podcasts de divulgação científica: levantamento exploratório dos formatos de programas brasileiros. 2020. 94 f. Trabalho de Conclusão de Curso (Especialização em Divulgação e Popularização da Ciência) - Museu da Vida, Casa de Oswaldo Cruz, Fundação Oswaldo Cruz; Casa da Ciência, Universidade Federal do Rio de Janeiro; Fundação Cecierj; Museu de Astronomia e Ciências Afins; Instituto de Pesquisas Jardim Botânico do Rio de Janeiro, Rio de Janeiro, 2020. Disponível em https://www. arca.fiocruz.br/handle/icict/46114. Acesso em: 14 fev. 2022.

FREIRE, Eugênio Paccelli Aguiar. Podcast: breve história de uma nova tecnologia educacional. Educação em Revista, Marília, v. 18, n. 2, p. 55-70, 2017. DOI: https://doi.org/10.36311/2236-5192.2017.v18n2.05.p55. Disponível em: https://revistas.marilia.unesp.br/index.php/educacaoemrevista/article/view/7414. Acesso em: 14 fev. 2022.

GIL, Antonio Carlos. Métodos e técnicas de pesquisa social. 6. ed. São Paulo: Atlas, 2008.

GUMS, Elyson et al. Pesquisa exploratória de podcasts brasileiros voltados à divulgação científica. In: CONGRESSO DE CIÊNCIAS DA COMUNICAÇÃO NA REGIÃO SUL, 20., 20-22 jun 2019, Porto Alegre. Anais [...]. Porto Alegre: Intercom, 2019. p.1-14. Disponível em: https://portalintercom.org.br/anais/sul2019/resumos/ R65-1708-1.pdf. Acesso em: 08 maio 2021.

HORST, Maja; DAVIES, Sarah R.; IRWIN, Alan. Reframing science communication. In: FELT, Ulrike; FOUCHÉ, Rayvon; MILLER Clark A.; SMITH-DOERR, Laurel (ed.). The handbook of science and technology studies. Cambridge: MIT Press, 2017. p. 881-907.

MENEZES JUNIOR, Luiz Antônio Alves de. Podcast IsulbraCast: sobre. [S. I.: s. n, 2019?]. Disponível em https://open.spotify.com/show/3XuL4yQLrRfXyNdx5dullE. Acesso em: 14 fev. 2022.

LIMA, Guilherme da Silva; GIORDAN, Marcelo. Da reformulação discursiva a uma práxis da cultura científica: reflexões sobre a divulgação científica. História, Ciências, Saúde - Manguinhos, Rio de Janeiro, v. 28, n. 2, p. 375-392, 2021. DOI: https://doi.org/10.1590/S0104-59702021000200003. Disponível em: https://www.scielo. br/j/hcsm/a/H85nxJBhL7gQXjhSKrFbQjk/. Acesso em: 14 fev. 2022.

LUIZ, Lucio; ASSIS, Pablo de. O podcast no Brasil e no mundo: um caminho para a distribuição de mídias digitais. In: CONGRESSO BRASILEIRO DE CIÊNCIAS DA COMUNICAÇÃO, 33., 2010, Caxias do Sul. Anais [...] Caxias do Sul: Intercom, 2010. p.1-15. Disponível em: http://www.intercom.org.br/papers/nacionais/2010/ resumos/R5-0302-1.pdf. Acesso em: 08 maio 2021.

MACKENZIE, Lewis E. Science podcasts: analysis of global production and output from 2004 to 2018. Royal Society Open Science, Londres, v. 6, n. 1, p. e180932, 2019. DOI: https://doi.org/10.1098/rsos.180932. Disponível em: https://royalsocietypublishing.org/doi/10.1098/rsos.180932. Acesso em: 14 fev. 2022.

MARQUES, Fabricio. Microfones abertos para a ciência. Revista Pesquisa Fapesp, São Paulo, n. 277, 2019. Comunicação. Disponível em: https://revistapesquisa.fapesp.br/microfones-abertos-para-a-ciencial. Acesso em: 08 maio 2021.

MERZAGORA, Matteo. Science on air: the role of radio in science communication. Journal of Science Communication, [s. I.], v. 3, n. 4, p. 1-7, 2004. DOI: https://doi.org/10.22323/2.03040302. Disponível em: https://jcom.sissa.it/archive/03/04/C030401/C030402. Acesso em: 14 fev. 2022.

MILLER, Steve. Public understanding of science at the crossroads. Public Understanding of Science, [s. I.], v. 10, n. 1, p. 115-120, 2001. DOI: https://doi.org/10.3109\%2Fa036859. Disponível em: https://journals.sagepub. com/doi/10.3109/a036859. Acesso em: 14 fev. 2022.

PACETE, Luiz Gustavo. No Brasil, 40\% dos internautas já ouviram podcast. Meio \& Mensagem, [s. I.], 13 maio 2019. Mídia. Disponível em: https://www.meioemensagem.com.br/home/midia/2019/05/13/no-brasil-40dos-internautas-ja-ouviram-podcast.html. Acesso em: 07 maio 2021.

PICARDI, Ilenia; REGINA, Simona. Science via podcast. Journal of Science Communication, [s. I.], v. 7, n. 2, C05, 2008. DOI: https://doi.org/10.22323/2.07020305. Disponivel em: https://jcom.sissa.it/archive/07/02/ Jcom0702\%282008\%29C01/Jcom0702\%282008\%29C05. Acesso em: 14 fev. 2022. 
POLITI, Cassio; ROSA, André. Conheça a história do podcast no mundo. Comunique-se, São Paulo, 27 mar. 2019. Disponível em: https://www.comunique-se.com.br/blog/conheca-a-historia-do-podcast-no-mundo/. Acesso em: 08 maio 2021.

POLIVANOV, Beatriz. Etnografia virtual, Netnografia ou apenas etnografia? Implicações dos termos em pesquisas qualitativas na internet. In: CONGRESSO BRASILEIRO DE CIÊNCIAS DA COMUNICAÇÃO, 36. 4-7 set. 2013, Manaus. Anais [...]. Manaus: Intercom, 2013. p. 1-15. Disponível em: http://www.intercom.org. br/papers/nacionais/2013/resumos/R8-0346-1.pdf. Acesso em: 08 maio 2021.

SANTOS, Francisco Edvander Pires. Informação científica por meio da produção de conteúdo em podcast: hospedagem, distribuição e agregadores. ConCl: Convergências em Ciência da Informação, Aracajú, v. 3, n. 2, p. 22-51, 2020. DOI: https://doi.org/10.33467/conci.v3i2.13453. Disponível em: https://seer.ufs.br/index. php/conci/article/view/13453. Acesso em: 14 fev. 2022.

SILVA, Fabiano Couto Corrêa da; D'ANDREA, Gabriela de Souza. Podcasts e webinars sobre covid-19 na área de ciência da informação. AtoZ: novas práticas em informação e conhecimento, Curitiba, v. 9, n. 2, p. 139-147, 2020. DOI: http://dx.doi.org/10.5380/atoz.v9i2.75860. Disponível em: https://revistas.ufpr.br/atoz/ article/view/75860. Acesso em: 14 fev. 2022.

SILVA, Sérgio Pinheiro da; SANTOS, Régis Salvarani dos. O que faz sucesso em podcast? Uma análise comparativa entre podcasts no Brasil e nos Estados Unidos em 2019. Radiofonias - Revista de Estudos em Mídia Sonora, Ouro Preto, v. 11, n. 1, p. 49-77, 2020. Disponível em: https://periodicos.ufop.br/radiofonias/ article/view/4317. Acesso em: 14 fev. 2022. 